\title{
ASSISTÊNCIA DE ENFERMAGEM A PACIENTES COM MANIFEST AÇOEES DE COMPORTAMENTO DECORRENTES DE SINTOMAS OBSESSIVO-COMPULSIVA
}

\author{
Marli Alves Rolim* \\ Marina Borges Teixeira* \\ Hideko Takeuchi Forcella*
}

ROLIM, M. A.; TEIXEIRA, M. B.; FORCELLA, H. T. Assistência de Enfermagem a pacientes com manifestaçбes de comportamento decorrentes de sintomas da neurose obsessivo-compulsiva. Rev. Esc. Enf. USP. São Paulo, 19(1): 47-53, 1985.

As autoras discutem os padrðes usuais de comportamento dos individuos neuróticos, com sintomas obsessivo-compulsivos, o significado deste comportamento e alguns dos principais pontos da assistência de enfermagem.

\section{INTRODUÇÃO}

O aumento dos distúrbios neuróticos, tão discutido mas dificilmente demonstrável, atualmente está sendo relacionado com as mudanças das condiçóes de vida que os individuos véem enfrentando no seu dia-a-dia. O confronto do individuo com a sociedade e os conflitos disso resultantes parecem ter muita importância para o desenvolvimento das neuroses. $O$ que se sabe é que as perturbações neuróticas são freqüentes e suas conseqüências sociais tão relevantes para os indivíduos que as apresentam, que merecem a atenção dos que trabalham na área da assistência psiquiátrica (SCHULTE \& TOLLE, 1981).

Para EY et alii (1981a), as neuroses são doenças da personalidade caracterizadas por conflitos intrapsíquicos que alteram a conduta social.

FENICHEL (1964) diz que os sintomas neuróticos decorrem essencialmente de insuficiência do sistema normal de controle, isto é, o indivíduo não tem condiçð̌es de usar de forma adequada seus mecanismos de defesa do ego. Segundo o mesmo autor, outra causa das neuroses pode ser o fato de o indi-

- Enfermeira. Mestre em Enfermagem. Professor Assistente do Departamento de Enfermagem Materno-Infantil e Psiquiátrica da Escola de Enfermagem da USP - disciplina Enfermagem Psiquiátrica. 
víduo, quando criança ter sido submetido a educação extremamente rígida, e daí decorrendo um superego muito exigente. Estes dois fatores, incapacidade de usar de forma adequada os mecanismos normais de defesa e superego muito exigente, podem desencadear no individuo ansiedade intensa que, se năo for controlada, poderá vir a ser o fator causal de quadros neuróticos.

COLEMAN (1973) assevera que nas perturbaçőes neuróticas existem tendências patológicas de desenvolvimento da personalidade, que levam o indivíduo a avaliaçőes errôneas de problemas ambientais, a conflitos graves e a ajustamentos pessoais e sociais inadequados. Para ele, tais tendências patológicas mostram, geralmente, uma longa história de desenvolvimento que, quase sempre, começa em relaçoes defeituosas entre pais e filhos, resultam em conduta imatura e em percepçðes deformadas do próprio eu e do mundo ambiente.

A incapacidade de usar de forma adequada os mecanismos de defesa do ego, citada por FENICHEL (1964), leva a pessoa neurótica a experimentar ansiedade com grande freqüência. Quando há a tentativa de controle desta ansiedade, por meio de mecanismos de defesa neuróticos, surgem os diversos sintomas que caracterizam as várias formas de perturbaçбes neuróticas: histérica (reaçð̃es dissociativa e de conversão), fóbica, hipocondríaca e obsessivo-compulsiva.

Embora as neuroses sejam vistas como menos maléficas que as psicoses, algumas neuroses são mais incapacitantes do que algumas psicoses. É o caso da neurose obsessivo-compulsiva que muitas vezes incapacita o indivíduo para o convívio social. Segundo HANUS (1981), esta é a mais grave e mais rebelde forma das perturbaçðes neuróticas.

No presente estudo vamos nos ater à neurose obsessivo-compulsiva.

Existem várias teorias que tentam explicar as causas desta neurose.

PAIM (1980) diz que a falta de segurança, restriçōes culturais e sentimento de culpa são fatores que podem vir a ser a causa do seu desenvolvimento em indivíduos predispostos.

Segundo ‘COLEMAN (1973), a pessoa com neurose obsessivo-compulsiva manifesta obsessð̃es ou pensamentos obsessivos e reaçőes compulsivas. POROT (1977) define obsessão como idéia associada a um sentimento penoso, em dualismo ídeo-afetivo, que invade a consciência de forma repetida e incoercivel.

Nas reaçð̃es obsessivas, as idéias são muito constantes, parecem irracionais para o paciente e interferem em seu comportamento diário; este pode ter a idéia obsessiva de matar a esposa com um punhal, de envenenar o filho, ou qualquer outro temor obsessivo de impulsos incontroláveis. Embora as idéias obsessivas nem sempre se traduzam em ação, continuam a ser uma 
fonte de tormento para o paciente, porque por mais que se esforce não consegue livrar-se delas; muitas vezes este sente que está ficando louco ou que não pode viver (COLEMAN, 1973).

Nas reações compulsivas, o paciente sente-se compelido a realizar algum ato que, mesmo durante o processo, parece absurdo e estranho a ele; esses atos variam de rituais simples, como de correr os dedos pelos cabelos, até atos rituais mais complicados, como, por exemplo, fazer exatamente sete vezes o laço da gravata, para se sentir livre de ansiedade. Apesar deste comportamento perturbar seriamente sua vida, após a execução do ato compulsivo o paciente experimenta, geralmente, sentimento de satisfação,enquanto que, se tentar conter a compulsão, é dominado por ansiedade crescente, que pode chegar à angústia (KOLB, 1980).

BUTCHER (1975) descreve os indivíduos que são propensos a desenvolver a neurose obsessivo-compulsiva com uma série de traços distintos de personalidade. $\mathrm{Na}$ maioria das vezes são pessoas introspectivas, repensam muito as coisas e se orgulham de seu intelecto e racionalidade; são muito preocupadas, tensas e irritáveis e têm dificuldade em chegar a decisð̃es práticas devido, à sua tendência à abulia e à dúvida; são sumamente perfeccionistas, tendendo a fixar padrões extremamente elevados para si próprias, e são muito críticas a respeito de outras pessoas; apresentam pouca capacidade para o divertimento e a espontaneidade, dai o fato de viverem uma vida muito ordenada, na tentativa de evitar imprevistos.

KOLB (1980) comenta que a origem das condutas obsessivo-compulsivas está nos primeiros esforços ou na luta da criança em crescimento, entre seus impulsos dirigidos para uma onipotente auto-afirmação e a necessidade de conformar-se com as exigências dos pais, para manter o seu amor e respeito. $O$ período inicial do treinamento dos hábitos de higiene é o início do conflito. Muitas vezes, o futuro indivíduo obsessivo é educado por uma rígida e compulsiva mãe, que insistentemente exige submissão e ameaça-o com falta de amor ou com várias formas de punição. A criança em crescimento está, pois, exposta a um repetido despertar de rancor, através das insistentes exigências de limpeza e submissão, mas precisa reprimir-se para manter a relação afetiva com seus pais.

Para BUTCHER (1975), a rígida consciência moral da pessoa com neurose obsessivo-compulsiva torna-lhe difícil aceitar pensamentos ou impulsos que contrariam os valores éticos, morais e sociais, por exemplo, os sentimentos agressivos e sexuais; para defender-se contra esses pensamentos inaceitáveis e ameaçadores, pode utilizar-se de um ou mais dos mecanismos abaixo referidos.

a) Substituição: substitui estes pensamentos por outros mais seguros.

b) Formação de reação: conduz-se de modo diretamente oposto ao que é impulsionado a conduzir-se. 
c) Anulação: tenta eliminar ou desfazer o ato não aceito, realizando um ritual; por exemplo, a lavagem compulsiva das mãos pode ser uma tentativa para limpar a pessoa da culpa, depois de ter percebido um ato imoral.

Para atender às exigências ambientais, as defesas obsessivo-compulsivas do indivíduo podem intensificar-se a ponto deste limitar sua vida significativamente, pois estas defesas, tornam-se ineficazes no alivio da ansiedade (HANUS, 1981).

Finalmente, EY et alii (1981b) define "a neurose obsessiva pelo caráter obrigatório (compulsivo) dos sentimentos, das idéias ou das condutas que se impõem ao indivíduo e o envolvem em uma luta inesgotável, sem que, entretanto, ele mesmo deixe de considerar este parasitismo incoercível como algo irrisório. Daí as características clássicas das obsessōes: incoercibilidade, automatismo, luta e consciência da doença".

\section{ASSISTÊNCIA DE ENFERMAGEM}

A assistência de enfermagem a ser prestada a qualquer pessoa deve ser individualizada, de acordo com suas necessidades, porém, existem determinados problemas comuns aos indivíduos cujo comportamento é decorrente de sintomas obsessivos e compulsivos; e os cuidados de enfermagem que lhes devem ser prestados são semelhantes.

O paciente com esse tipo de comportamento é, geralmente, uma pessoa rígida, meticulosa, com temor de enfrentar novas experiências e com sérias restriçōes ao seu viver devido as suas defesas neuróticas. Muitas vezes, é vagaroso e minucioso no que faz e pode demonstrar grande preocupação em fazer aquilo que é correto; por isso, por diversas vezes questiona os que o rodeiam para se assegurar se aquilo que faz está correto. Deste modo ele pode parecer muito possessivo e controlador do seu meio-ambiente; comportamento que pode provocar ressentimentos em outras pessoas.

Ele acaba por executar, periodicamente, uma espécie de ritual como mecanismo de defesa contra a ansiedade causada pelos sintomas obsessivos. $\mathrm{O}$ principal problema que estes pacientes apresentam é a falta de controle sobre a ansiedade e sobre seus sintomas e, como conseqüência, a necessidade da realização do ritual.

Como estes indivíduos são conscientes da irracionalidade de seus atos, percebem o ressentimento que seu comportamento provoca nas demais pessoas e, muitas vezes, podem tornar-se alvo de zombaria, devido ao ritual, até mesmo por parte de pessoas que os assistem. Por outro lado, a impossibilidade de realizarem seu ritual, quando impedidos por pessoas menos esclarecidas, leva ao aumento da sua ansiedade. Consequentemente, evitar a ocorrência destes fatos passa a constituir um sério problema para a equipe de enfermagem. 
Às vezes, estes pacientes apresentam graves quadros de infecção porque sua tendência à meticulosidade quanto à aparência e limpeza leva-os ao uso de produtos abrasivos na sua higiene pessoal. Houve casos de pessoas que lavavam as mãos com palha de aço e outros que utilizavam a água sanitária para sua limpeza corporal. Além desses problemas, pode também surgir a fadiga, dependendo do ritual utilizado e, às vezes, alguns chegam a perder o controle sobre o próprio comportamento, se houver alguma mudança na rotina hospitalar de vida diária ou no esquema usual de suas atividades.

Estabelecer relacionamento com o paciente neurótico geralmente é menos difícil do que com pacientes psicóticos; a comunicação terapêutica torna-se mais fácil; contudo, a enfermeira que o assiste pode encontrar dificuldade em aceitar o comportamento do paciente de utilizar freqüentemente rituais para enfrentar a ansiedade. Outro sério problema enfrentado pela enfermeira é conseguir desviar a atenção do paciente na tentativa de evitar que ele inicie o ritual, uma vez que, se iniciado e interrompido, o paciente sente necessidade incoercivel de recomeçá-lo e isto pode provocar mais ansiedade tanto nele como no pessoal que o assiste.

Em decorrência disto, a enfermeira poderá experimentar ansiedade e sentimento de impotência em face do insucesso de tentar mudar o comportamento do paciente, pois é muito raro que o mesmo consiga se livrar de seus sintomas obsessivo-compulsivos.

Dispor de tempo suficiente para que o paciente possa realizar seu ritual é outro problema que a enfermeira precisa enfrentar, uma vez que os rituais costumam ser demorados e podem atrapalhar as atividades rotineiras dos outros pacientes (refeições, banho, etc) e do pessoal que atua na unidade.

Ao assistir o paciente com este comportamento, a enfermeira deve ter como objetivo principal levá-lo a encontrar modos eficientes de lidar com a ansiedade.

É útil para a enfermeira fazer concessões ao fator tempo, isto é, ser condescendente com relação a esse aspecto; prevendo que esse paciente pode ser vagaroso e minucioso em tudo o que faz, e dando-lhe tempo, o paciente vai se sentir muito menos pressionado; é de valiosa ajuda, também, começar a prepará-lo, para determinadas atividades, um pouco antes do que o faria com outros pacientes, a fim de previnir possíveis atrasos nas atividades rotineiras da unidade.

A enfermeira não deverá interferir ou impedir que o paciente leve a cabo o seu ritual e muito menos apressá-lo, a não ser nos casos em que o ritual provoque danos sérios à saúde do mesmo; o que pode ser feito é tentar ocupá-lo, desenvolvendo com ele um programa de atividades diárias.

Outro aspecto que não deve ser esquecido na assistência de enfermagem é que o paciente pode querer que outros participem de seus rituais, pois este 
comportamento é reflexo da sua necessidade de controlar o ambiente. A enfermeira deverá estar alerta para a hostilidade que tal controle pode provocar nos outros, uma vez que estes acontecimentos farão o paciente sentir mais culpa e, conseqüentemente, aumentarão a sua necessidade de controle. Isto porque este paciente é extremamente sensível a críticas e está sempre pronto para sentir culpa. Cabe à enfermeira orientar os outros quanto a este tipo de comportamento e proteger o paciente.

Quando houver necessidade de mudanças nas rotinas, é de grande valia que estas sejam introduzidas gradativamente, para que assim o paciente não se sinta mais ansioso em face da nova situação.

Ao se relacionar com este paciente, a enfermeira deve mostrar aceitação pela sua pessoa e ser sincera nas suas interaçס̃es com ele, mesmo que este apresente demonstraçóes dissimuladas de agressividade, como o sarcasmo e a ironia; ele, como toda pessoa neurótica, tem dificuldade em expressar abertamente sentimentos hostis; daí essa tendência a comportamentos agressivos complicados e dissimulados (EY et alii, 1981a).

Deve a enfermeira, também, ajudá-lo a exprimir seus sentimentos hostis sem que experimente ansiedade ou sentimento de culpa, posteriormente.

Uma vez que o paciente se sente constantemente desvalorizado e com forte necessidade de aprovação, a enfermeira deve elogiá-lo sem conotação de julgamento quando ele conseguir desempenhar as suas atividades; deve também selecionar atividades pelas quais ele realmente se interesse e, assim, poder experimentar sentimentos de realização.

A enfermeira deve ter em mente que de nada adianta discutir ou criticar racionalmente com o paciente, o seu comportamento, já que este, em geral, reconhece a irracionalidade de seus atos; isto só iria aumentar seu sentimento de culpa.

Não podem ser esquecido, também os cuidados básicos de enfermagem relativos aos problemas somáticos e d fadiga que estes pacientes possam apresentar; eles devem repousar periodicamente e receber cuidados específicos para cada problema somático apresentado.

A irritação, o cansaço e a ansiedade que este paciente provoca nos membros da equipe de enfermagem, devido ao seu comportamento e às suas características de personalidade, podem ser evitados se houver rodízio constante do pessoal que o assiste. Orientação constante dos funcionários é indispensável.

A orientação dos familiares constitui um dos aspectos importantes da assistência de enfermagem. A família deve ser orientada a não criticar o comportamento do paciente, não ridicularizá-lo; deve estar ciente de que todo o seu comportamento é decorrente da doença e de que, freqüentemente, com a internação, ocorre remissão de algumas manifestações de comportamento, 
mas muitas delas persistem. Deve ser reforçado que o apoio da família é indispensável para a reintegração deste paciente dentro do seio familiar e da comunidade.

ROLIM, M. A.; TEIXEIRA, M. B.; FORCELLA, H. T. Nursing care to patients with obsessive-compulsive symptoms. Rev. Esc. Enf. USP, São Paulo, 19(1): 47.53, 1985.

The authors discuss the usual behavior patterns of neurotic patients with obsessive-compulsive symptoms, the meaning of this behavior and some of the main points in nursing care.

\section{REFERÊNCIAS BIBLIOGRÁFICAS}

1. BUTCHER, J. N. Neuroses. In: p. 39-55.

2. COLEMAN, J. C. Perturbaçбes neuróticas. In: temporânea. Sáo Paulo, Pioneira, 1973. cap. 6, p. 265-340.

3. EY, $\mathrm{H}$. et alii. As neuroses. In: 1981a. cap. 2, p. 421-46.
A neurose obsessiva. In:

4. 1981a. cap. 2, p. $421-46$.

Manual de psiquiatria. Rio de Janeiro, Masson do Brasil, Brasil, 1981 b. cap. 6, p. 490-505.

5. FENICHEL, $O$. Los puntos de vista dinamico, economico y estructural. In: coanalítica de las neuroses. 2. ed. Buenos Aires, Paidós, 1964. cap. 2, p. 25-36.

6. HANUS, M. Neurose obsessiva. In: 187-97.

7. KOLB, L. C. As neuroses. In: 1980. cap. 22, p. 379-417.

Psicologia do anormal. Såo Paulo, Cultrix, 1975. cap. 3, IM, I. Neuroses. In: nas, 1980 . cap. $19, \overline{\text { p. } 439-61 \text {. }}$

9. POROT, A. Dicionário de psiquiatria. 3. ed. Labor, Barcelona, 1977. p. 844.

10. SCHULTE, N. \& TÖLLE, R. Neuroses. In: P. U., 1981. cap. 2, p. 32-90. Manual de psiquiatria. 4. ed. São Paulo, E.

\section{BIBLIOGRAFIA}

1. HOFLING, C. K. et alii. Transtornos neuróticos: neuroses traumáticas y psiconeuroses. In: Enfermería psiquiátrica. 2. ed. México, Interamericana, 1970.

2. MATHENEY, R. V. \& TOPALIS, M. Aberraciones de la conduta. In: quiátrica. 5. ed. México, Interamericana, 1971. cap. 4, p. $52-64$.

3. MERENESS, D. \& KARNOSH, L. J. Pacientes cuya conducta se caracteriza por síntomas neuróticos. In: Elementos de enfermería psiquiátrica. México, Prensa Médica Mexicana, 1964. cap. 15, p. 194-208. 